أبحاث المؤتمر العلمي الدولي الثاني نقابة الاكاديميين العراقيين/ مركز التطوير الاستراتيجي التئي

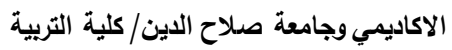

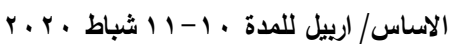
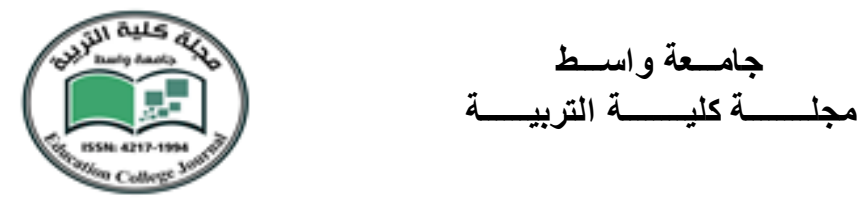

\title{
عناصر الجذب البصري في عروض مسرح الطفل
}

أ.م.د. ميادة مجيد أمين الباجلان المحترمة معهد القنون الجميلة - تربية صلاح الدين الدين Mayadameme68@gmail.com

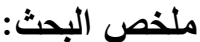

يعد العناصر البصرية للمنظر المسرحي من أهم العناصر ذات التأثثر المباشر على المنلقي

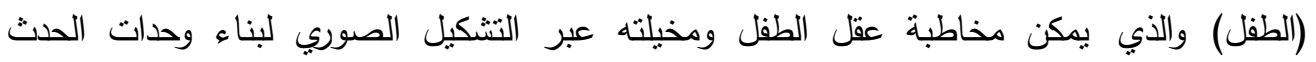

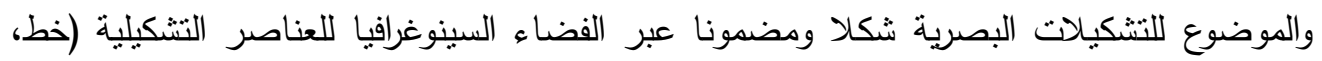

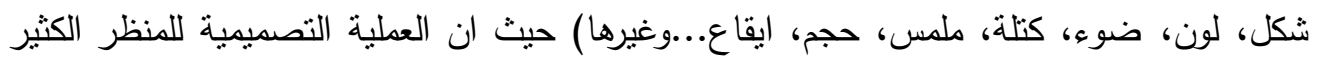

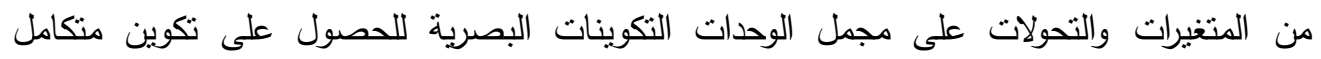

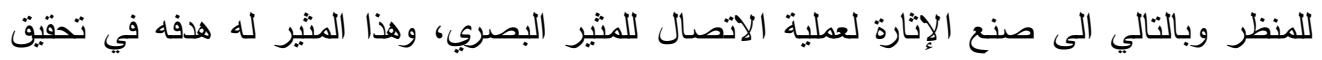

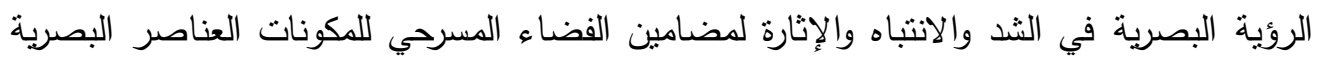

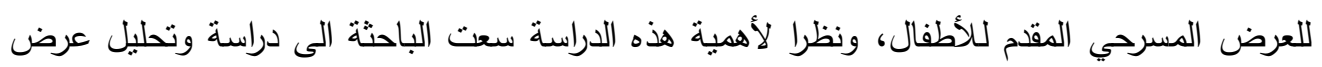

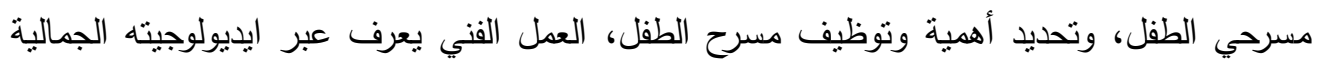
تترك الأثر الإبداعي من خلال خطاباته الفنية والجمالية .

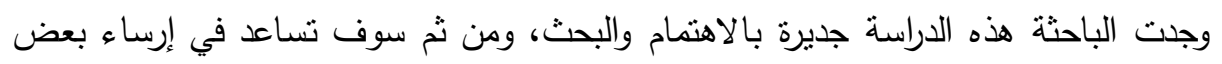
المرنكزات التصميمية الهامة في عروض مسرح الطفل، وحدد مشكلة البحث على وفق التساؤل الآتي: (كيفية اشتغال عناصر الجذب البصري في عروض مسرح الطفل) •

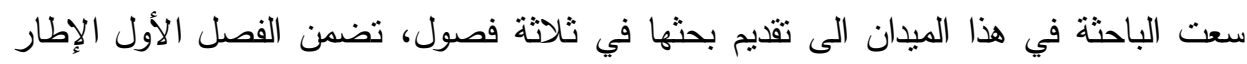

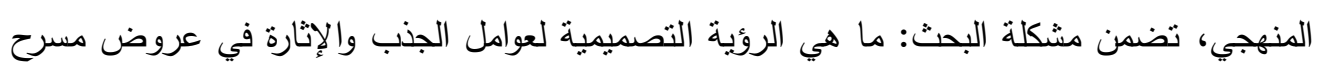

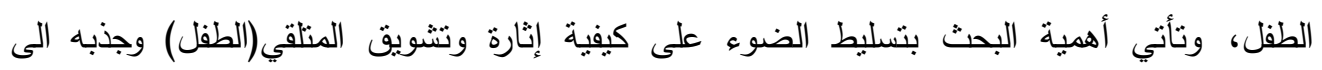

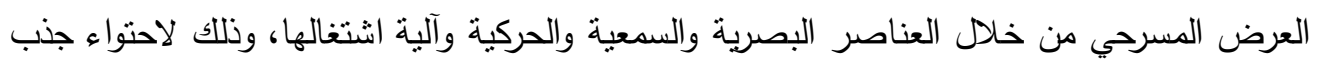
الطفل ومتابعة العرض بتفاعلية مستمرة، وحدد هدف البحث باستكثاف عوامل الجذب والإثارة، وكيفية

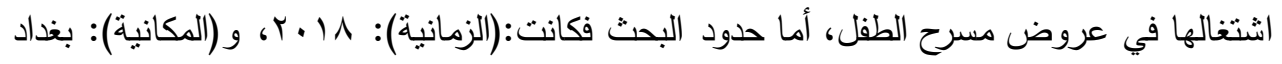

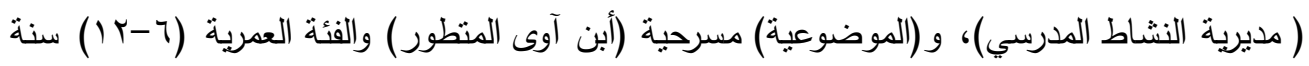

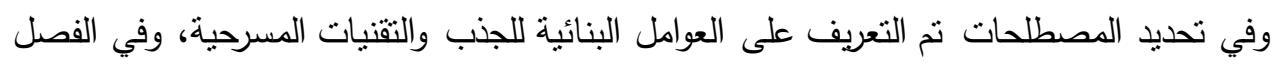


أبحاث المؤتمر العلمي الدولي الثاني نقابة

الاكاديميين العراقيين/ مركز التطوير الاستراتيجي التئي

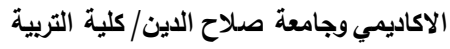

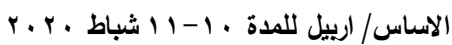
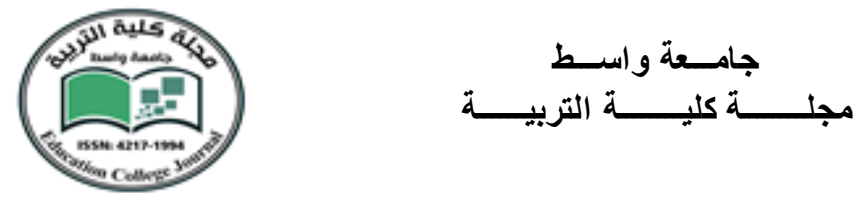

الثاني (الاطار النظري) كان في مبحثين بعنوان المبحث الأول: توظيف العناصر البصرية للخطاب الموجهة في عروض مسرح الطفل

تتاولت الباحثة عن عوامل الجذب والإثارة البصرية للتراكيب البنائية في العملية التصميمية، والاشتغال الجمالي للعناصر البصرية في المنجز الفني الذي يسهم في عملية التشويق في الإحساس والانتباه والإدراك، أما المبحث الثاني: الجذب البصري والتراكيب البنائية في العملية التصميمية في عروض مسرح الطفل: تتاولت الباحثة بناء الروئة التصميمية وسماتها الجمالية والفكرية للعرض وآلية اشتغالها في عروض مسرح الطفل، وفي مؤشرات ومعطيات الاطار النظري جاء أبرزها: يوظف المصدم في تأسيسه لعناصر التشكيل البصري للعرض المسرحي للسيطرة على جذب وإنتباه المتلقي(الطفل) لصياغة فضاءات جديدة وفقا لبناء منظومة بصرية، سمعية، حركية، ومعاني تحمل دلالات عديدة للمتلقي(الطفل) تتمي خيال الطفل بجانب المتعة ومفاهيم فكرية وجمالية . وفي الفصل الثالث إجراءات البحث تتاولت الباحثة مجتمع البحث في تحليل عينة مسرحية للأطفال وأدوات التحليل ومنهج البحث الوصفي وعينة البحث( ابن آوى المتطور) وفقا للمعطيات، ومؤشرات الاطار النظري، وفي نهاية التحليل موجز لنتائج التحليل تضمن عدة فقرات وكانت أبرزها هي بساطة العمل والوضوح في مفردات العرض المسرحي للأطفال، وفي اللغة، والشخصيات المختلفة الأنسية وغير الأنسية وتشكيلها مع حركة الإضاءة، والموسيقى والمؤثرات الموسيقى والتي لعبت دورا فاعلا في تحريك المشاعر والأحاسيس، والتي أثنتت حضورا فعليا في عنصر الجذب والإثارة والتشويق، وفي التوصيات أوصت الباحثة في إقامة دورات وورش تدريبية للمهتمين والمقيمين على ولى مسارح الطفل، وقدت الباحثة مقترحا (اشتغال عوامل الجنب للتقنيات البصرية الحديثة في عروض مسرح الطفل)، وأختتم البحث بقائمة المصادر والمراجع والملاحق والصور ، وخلاصة البحث باللغة الإنكليزية.

\section{Abstract}

The researcher strove in this field to study the most important visual elements and the mechanism of their work in child theater shows to achieve visual attraction, in the direct impact and immediate interaction of the child, and to present her research in three chapters, the first chapter included the methodological framework, the research problem included: What is the design vision of attractions and excitement In children's theater shows? The importance of the research comes by highlighting how to excite and excite the recipient (the child) and attract him to the theatrical performance through 
أبحاث المؤتمر العلمي الدولي الثاني نقابة

الاكاديميين العراقيين/ مركز التطوير الاستراتيجي

الاكاديمي وجامعة صلاح الدين/كلية التربية الاكية الادين

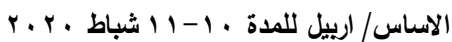
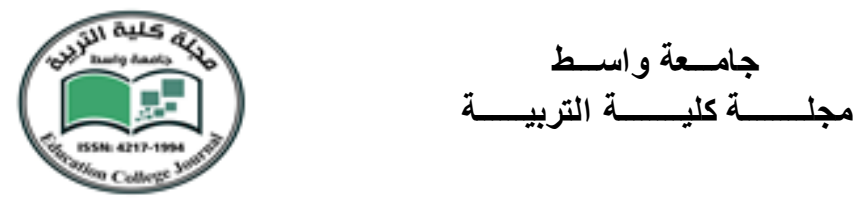

visual, auditory, and motor elements and the mechanism of its operation, in order to contain the attraction of the child and follow-up to the show with continuous interaction. As for the limits of the research, they were: (temporal): 2018, and (spatial): Baghdad (directorate of school activity), (objective) play (Ibn Awa Almotatwer) and age group (6-12) years, and in defining the terms, the structural factors were defined. Attractive and theatrical techniques.

The second chapter (theoretical framework) included in two topics, the first topic: the employment of the visual elements of the speech addressed in the children's theater shows. The researcher discussed the factors of attraction and visual excitement of the structural compositions in the design process, and the aesthetic work of the visual elements in the artistic achievement that contributes to the process of suspense in sensation, attention and perception, while the second topic: visual attraction and structural compositions in the design process in child theater performances: the researcher dealt with building the vision The design and its aesthetic and intellectual attributes of the show and its mechanism of operating in child theater shows, in addition to the theoretical framework indicators. The third chapter included the research procedures, the researcher addressed the research community in analyzing a children's theatrical sample, analysis tools, descriptive research method and the research sample (advanced jackal) according to the data, theoretical framework indicators, and at the end of the analysis a summary of the results of the analysis, and the recommendations that the researcher recommended in setting up courses and training workshops for those interested And the residents of the children's theaters, and the researcher presented a proposal (working the attractions of modern visual techniques in the children's theater shows), and concluded the research with a list of sources, references, appendices and pictures, and the research summary in English. 
أبحاث المؤتمر العلمي الدولي الثاني نقابة الاكاديميين العراقيين/ مركز التطوير الاستراتيجي التئي

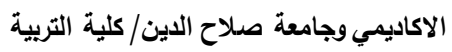

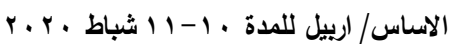
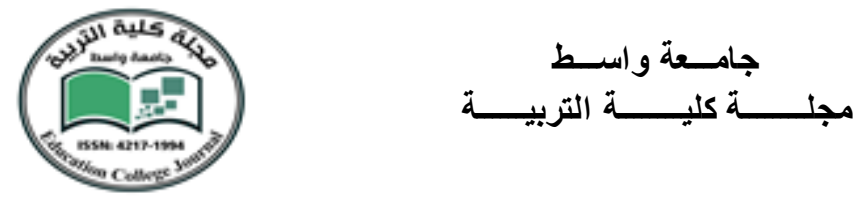

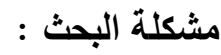

إن أسس توظيف العناصر البصرية للخطاب الموجه في عروض مسرح الطفل لابد من أن تمتاز

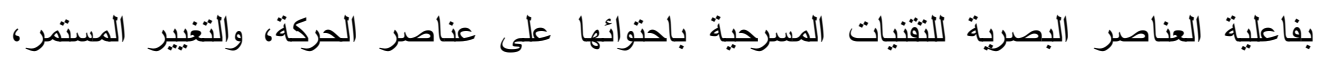
والقادرة على التفاعل والجذب مع تقنيات المسارح الحديثة حتى على مستوى استعمال الثاشات،

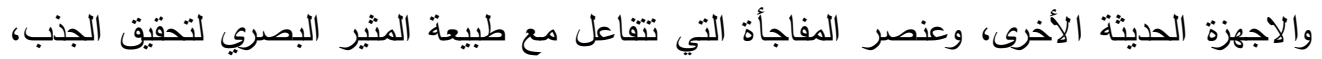

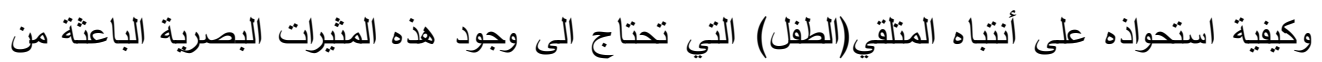

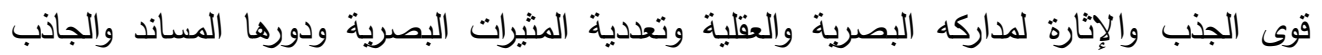

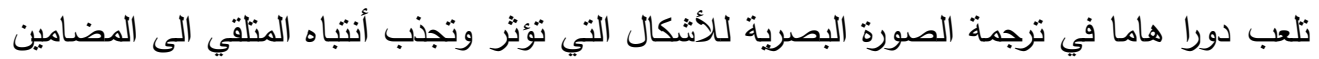
والقيم والرسائل المراد توصيلها، فعناصر الأثكال البصرية يبدعها الفنان المصمم في عملية نوظيف

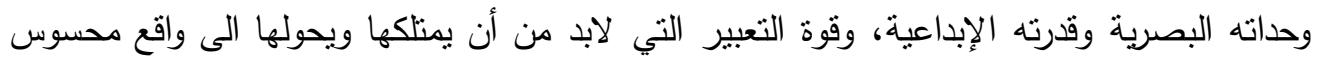

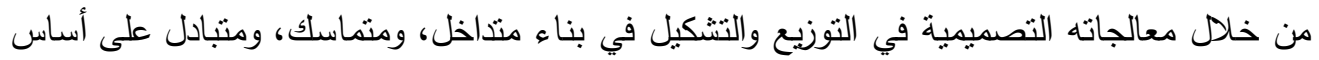
التتوع التي نحقق الجذب للانتباه لينتج عنه تأثيرا يجذب المنلقي (الطفل)، وبالرغم من أن أن المسارح العالمية قطعت شوطا واسعا نحو استعمال تقنيات مذهلة في عروضها فإنها لم تدخل وبشكل جدي في مجال النطبيق العملي في العراق، ولم ينم استثمارها بشكل فعال، حيث وجلت الباحثة هذه الدراسة جديرة بالاهتمام والبحث، والتي قد تساعد في إرساء بعض المرتكزات التصميمية الهامة في عروض لفال مسرح الطفل، وحدد مشكلة البحث على وفق التساؤل الآتي: (كيفية اثتغال عناصر الجنب البصري

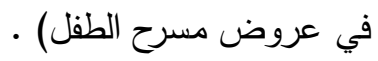

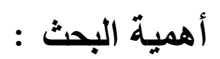

تعد دراسة موضوع الجنب البصري من المبادئ المهمة في العملية التصميمية حيث تسهم في نطوير العلاقات الادائية وايضاح الجوانب الفكرية والجمالية، ينهض بالتنكيل البصري على وفق تصورات المصمين والمخرجين، وعناصر التكوين، لخلق الجذب والإثارة، وتأتي أهمية البحث بتسليط الضوء على كيفية إثارة وتتويق المنلقي(الطفل) وجذبه الى العرض المسرحي من خلال العناصر البصرية والسمعية والحركية وآلية اشتغالها، وذلك لاحتواء جذب الطفل ومتابعة العرض بتفاعلية

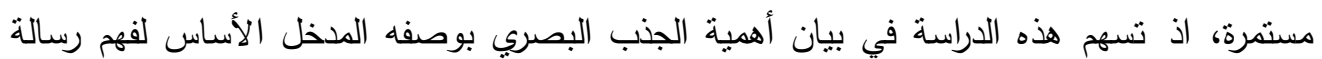

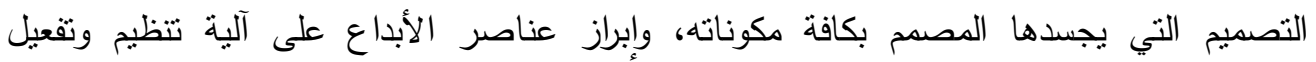
التصميم بما يتتاسب ومدارك الأطفال وتلك النطورات، لذا فإن الاهتمام وتسليط الضوء على هكذا لألها 
أبحاث المؤتمر العلمي الدولي الثاني نقابة الاكاديميين العراقيين/ مركز التطوير الاستراتيجي التئي

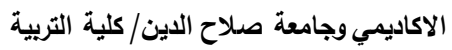

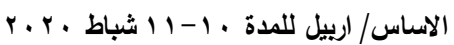
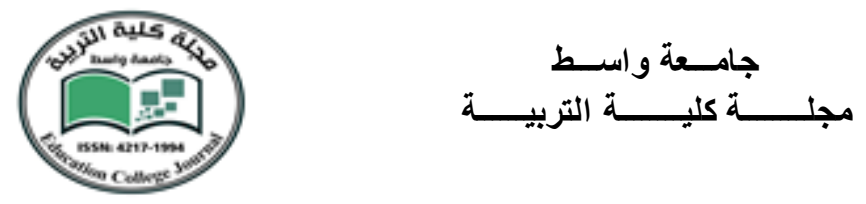

موضوع ينفع الدارسين والمختصبن والعاملين في حقل المسرح الموجه للأطفال ولا سيما الذبن بعطون

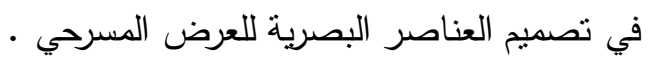

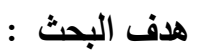

يهذف البحث التعرف على عوامل عناصر الجنب والإثارة ، وكيفية اثتغالها في عروض مسرح

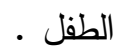

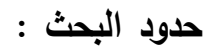

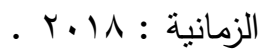
المكانية : بغداد ( مديرية النشاط المدرسي).

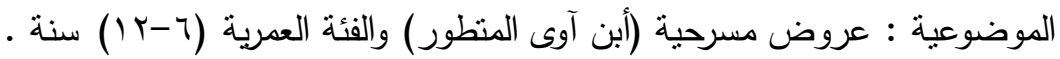
تحليد المصطلحات :

الجذب : (الجذب):"هو نشاط انتقائي يميز الحياة العقلية، ويمتل ما يمكن أن تدرك من أشياء من خلال صفاتها الإيجابية التي تجعلنا نجنذب إليها، وينتج عنه التشويق، والمتعة، والانسجام، والإثراء، وحب المكوث والارتباط بالمكان "( (1) الجذب البصري: هي عملية عقلية وسيكولوجية تتحقق بانفعال عضو حسي معين فيتولد شعور مفعم

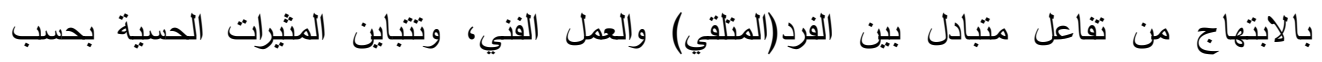
المصدر بشكل عام وتتدرج من أعلى المثير (حاسة البصر) ثم الاستثارة الحسية بالحركة والاهتزاز

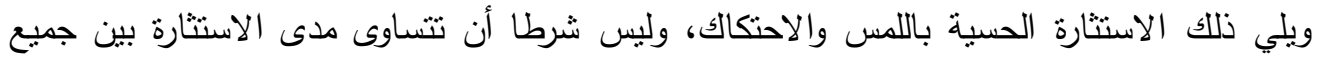
الأفراد، بل يعتد ذلك مدى الاستجابة الانفعالية من فرد لآخر (ץ).

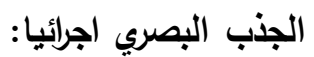

(علية شد انتباه المنلقي لمثيرات العرض الفني البصري للمثيرات الحسية من خلد تنظيم العناصر البصرية المترابطة والمنسجمة، والمتوافقة ينتج عنه التنشويق، والمتعة، وفق العلاقة الجمالية والفكرية تثري وتسهم في قوة الجذب والتفاعل، والتبادل، والاستجابة) فيثير مشاعرهم وحواسهم، وقيما تسهم في الخطاب الموجه إليهم) . مسرح الطقل: تعرفه ( وينفريد وارد ) (المسرح الموجه للأطفال وملتزم بتقديم أفكار جديدة واخراج شيق، جمهوره من الصغار وتعريفهر بألوان مختلفة من الفن)"( (؟). 
أبحاث المؤتمر العلمي الدولي الثاني نقابة

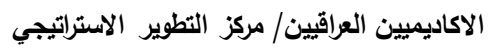

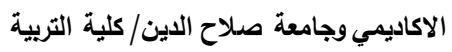

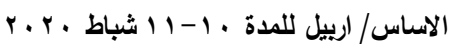
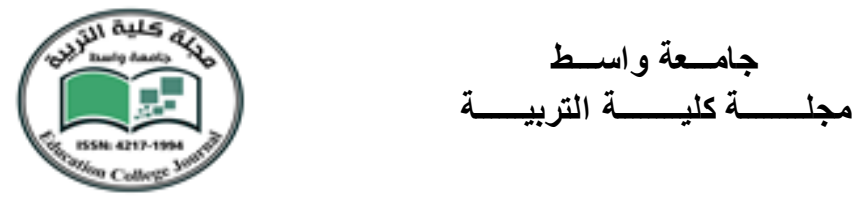

التعريف الاجرائي : هو ذلك العمل المسرحي الموجه للأطفال بتقنيات بصرية جاذبة ومثيرة بهدف إلى غاية جمالية وتربوية وتثقيفية، وإثارة مدركاتهم العقلية بما يتلاعم ومرحلتهم النمائية حسيا وذهنيا وانفعاليا وعاطفيا ولغويـا، والذي يراعي متطلبات خصائصسه العمريـة والبيئية، وتوجيهه نوجيها تربويا صالحا .

المبحث الأول: توظيف العناصر البصرية للخطاب الموجه في العرض الموجه للأطفال إن هدف المسرح هو خدمة المجتمع والإنسان، ولعل المسرح خير معلم إذ يلعب دورا أساسيا في تحقيق ميول المنلقي(الطفل) واتجاهاته وتعليمه وتربيته وتتمية الإحساس والإدراك لديه، لذا تبرز أهمية البحث من خلال مفهوم عناصر الجذب البصري في التراكيب البنائية للعملية التصميمية لعناصر العرض المسرحي المقدم للأطفال، والتي تعد حلقة مهمة في العملية الاتصالية تعتمد أسس العلاقات البنائية التصميمية واسهام المثيرات البصرية وأثزها في مستوى الاداء الفكري والوظيفي والجمالي وجعله وحدة منسجمة وإيقاعا منتظما العناصر البصرية (المنظر، والزي، والملحقات، والإضاءة، والمؤثرات الضوئية) ومالها من نأثير مباشر في حواس المنلقي (الطفل) وتحفيزه وجذبه، ولمسرح الطفل خصوصية في التعامل مع القيم الدراماتيكية، والني تعد من أهم مكونات العرض الدرامي (المسرحي) التي يعمل المخرج والمصمح في ضوئها، إذ يبدأ التركيز على ما يتتاسب والروئية أو المعالجة الإخراجية وللقيم الموجودة في النص (الفكرة، العقدة الثخصية، الحوار، الجو النفسي العام) تجعل العرض ذا تأثير حسي، فكري، جمالي في المتلقي(الطفل) وتضفي عليه ألق التكامل الفني على المستوبين(الثكل، والمضمون) بما بنسجم مع قيم ومدركات الطفل الحسية، والعقلية، مما يعزز ويرفع من تأثير القيمة الجمالية لعموم العرض المسرحي وذلك بقدر ما يجد المتلقي فيه نشويقا وإثارة، ومتعة

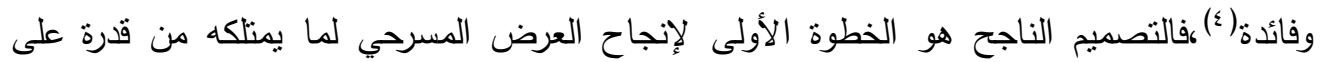
جذب وشد انتباه المنلقي( الطفل)، فمسرح اليوم بحاجة الى تقنيين ذي خيال واسع في صناعة صورة تثير الانتباه والجذب، والتي تمنل في جوهرها تحقيقا لخيالات ورؤى المسرحيين(تقنيين ومخرجين) في تجسيد وتجديد المسرح شكلا ومضمونا، في تشكيل وخلق فضاء خاص للعرض، لتحقيق رؤية منكاملة على وفق نظام وبناء عرض مركب يحمل سلسلة متتوعة للعناصر البصرية المثيرة . المسرح بوصفه وسيلة تعليمية تربوية "أثتبت فاعليتها في تلبية حاجات المتلقين بأسلوب لا يخلو عن الإثارة والتشويق لتحقيق المتعة والفائدة، فهي تتمي في المنلقي(الطفل) الحواس من خلال اللعب الدرامي والتعبير الحركي، وتتمية مهارة التفكير بأسلوب مشوق، وإكسابه مهارات التفكير الناقد، وتتمية المرونة في التفكير والإحساس بالمسؤولية، وإشباع فضوله عن طريق تقديم الخبرات المتتوعة، 
أبحاث المؤتمر العلمي الدولي الثاني نقابة

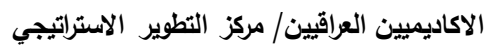

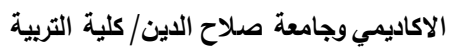

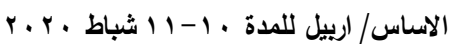
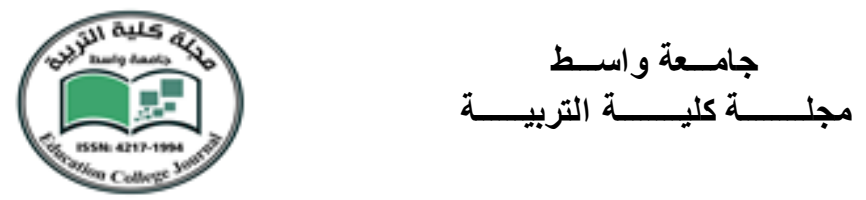

واعطائه الفرصة لتجريب مواقف حياتية، واكتشاف البيئة، واكساب صفات وأخلاق سلوكية اجتماعية

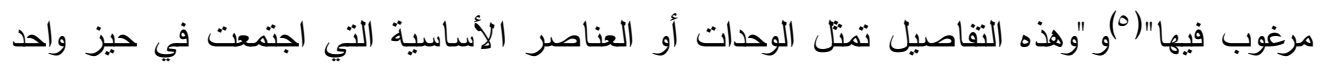
لتولد حركة الثكل الفني، وقيمه الجمالية والفنية والمثيرة من خلال الفكرة والفعل الذي ترجمه المصمح من بنات أفكاره الى واقع افتراضي فوق خشبة المسرح، متفاعلا مع الروئية الإخراجية، والخطة الحركية(الميزانسين)،فالعناصر البصرية التشكيلية منل الخط، واللون، والكتلة.. وغيرها، وما تثيره من إيحاءات لا تمنل قيمة جوهرية في ذاتها، وإنما قيمتها تتوقف على ارتباطها بالطاقة الإبداعية التي هيأت ظهور نأثيرها في العمل الفني الذي استجاب لخيال الفنان"(")، يصبح الطفل ماهرا في استخدام الأشياء، ويبدأ بإظهار انفعالاته العصبية وإحساساته بعمق تجاه الجمادات حوله، والمتمثلة بالتحدي الذي يبديه الحائط العالي الذي لا يستطيع الى أعلاه وصولا ليشعر بقمته، ولكنه يحصل على انطباع عن كنة ذلك الثيء بقذفه بكرة إليه، وبهذا يكتشف أنه يختلف كليا عن قطعة القماش المتوترة

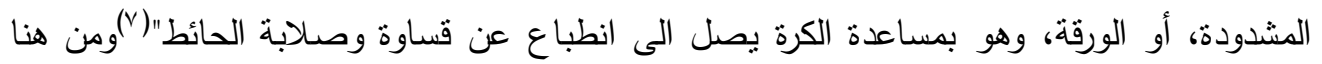
يستطيع الطفل عن قوة جنب الكرة عند الرمي، فللطفل خاصية في التوجه المباشر نحو الأشياء المؤثرة، ويزبد انتباهه عادة الى الأشياء الجديدة ،وغير مألوفة سابقا وفي قدرته على تذوق التصاميم البسيطة للأشكال والصور المعبرة بوضوح عن حيثيات الواقع البيئي. ويستحب تهيئة الأطفال للمشاهدة والمشاركة في العروض المسرحية المتتوعة لتتمية ذائقته الفنية، وهذا ما حيث (دلت التجارب على أن مشاهدة الأطفال لأحسن أنواع الدراما تجعلهم أكثر تذوقا للمسرحيات الجديدة حين

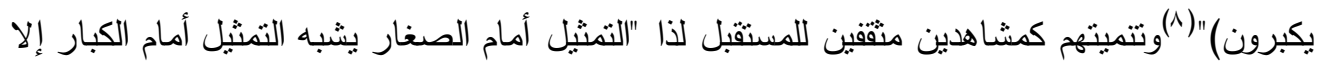
أنه يكون بصورة أفضل وأوضح وأنقى، ويقبل الأطفال على مسرحهم وكأنهم ذاهبون للاحتفال بالعيد

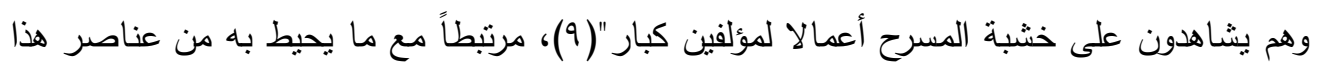
إذا عرفنا أن خبرة الطفل الحياتية قليلة جداً مما يجعل من الممكن إقناع الطفل أن (الشجرة) الواحدة الموضوعة على المنصة تمثل أو ترمز الى غابة واسعة وكثيفة وأن (الباب) أو (الثباك) يرمز الى هي المنزل شربطة أن يتسم ما موجود على المسرح بالمبالغة في الحجوم، لجذبه .

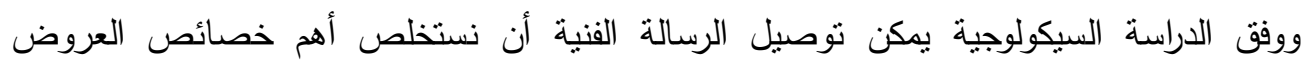
أمسرحية التي تقدم للأطفال : أ - موضوعات وأهداف اجتماعية وتربوية متتوعة تعمل على مناقشة المشكلات التي يتعرض لها الطفل في البيئة التي يعيش فيها وتقدم بشكل جاذب وممتع وشيق •

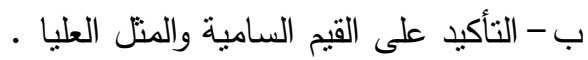


أبحاث المؤتمر العلمي الدولي الثاني نقابة

الاكاديميين العراقيين/ مركز التطوير الاستراتيجي التئي

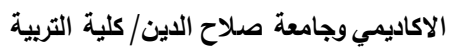

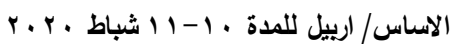
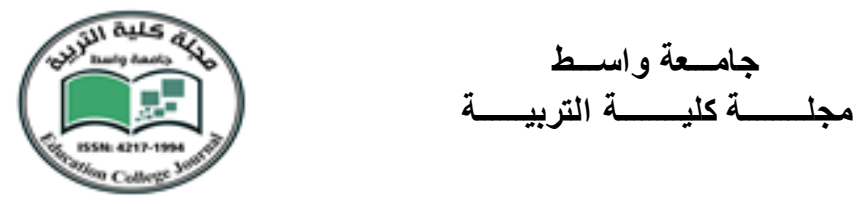

تلعب اهتمامات المنلقي (الطفل) وميوله في المثيرات المراد تعلمها دورا مهما في جذب الانتباه نحو ذلك، فكلما كان المثير من صلب اهتمامه ازداد انتباهه لذلك المثير وعمل من أجل إنجازه"(·) ،مما يزيد شدة انتباهه للتك المثير، إذ ويرى "الفيلسوف (فرويد) أن الفن وسيلة لتحقيق الرغبات في الخيال، تلك الرغبات التي أحبطها الواقع، ويؤكد على جدة وقيمة عمل الفنان لعالم الطفل الأيهامي والخيالي، فطبيعة النشاط الفني باعنباره مستمدا من نشاط اللعب لدى الأطفال، ومن ذكريات

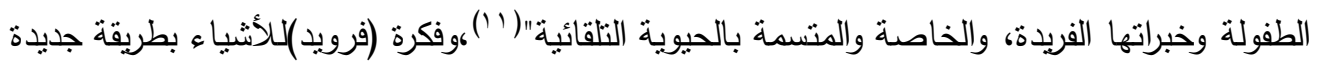
فكرة لها ملائمتها والتي يحتاج المتلقي(الطفل) الذي يبحث عن اللعب والترفيه والتسلية أن تكون الأعمال المقدة له قرببة الى واقعه، وبما يتتاسب إدراكه بعيدا عن التجربد أو التعبير الرهزي، ويبحث مسرح الطفل "يحتوي على قيم منتوعة منها على مستوى الثخصية المقدمة ومنها على المستوى الجمالي للعرض ومنها على المستوى التربوي وهذه القيم بتفاصيلها الفرعية يمكن ان تخلق معايير خاصة على مستوى العرض تتنجها هذه القيم اي ان المؤشرات التي توفرها القيم المتتوعة من الممكن ان توجد معايير خاصة على مستوى الشخصية المسرحية واداء الممنل لها ومنها الفعل والحدث والبناء السيكولوجي، وعلى مستوى القيم الجمالية مثنا تتنج لنا الكتل والخطوط والالوان وغيرها حالة من البناء السينوغرافي في العرض المسرحي للأطفال"(r'). عن خبرات ومثيرات بصرية جديدة، ومهمة الفنان المصمم في إنتاج تصميم في ضوء الخبرة الإنسانية والثروط الخاصة بمسرح الأطفال من خلال أنماط معينة مميزة للمثيرات الجمالية ـ فأصبحت الصورة التشكيلية دائما في حالة جديدة تعكس روح المجتمع والعصر • ويرى الفيلسوف(كانت)أن الجميل هو يرجع الى الذات وفق اشتراطات تقرضها الذات على الموضوع ، فيجعل من الحكم الجمالي ينشأ من الخاص لينتقل الى العام ... فيتحدد الجميل وفق اشتراطات حكم الذات، لذا يتخذ الخيال في الموقف الجمالي بعدين أساسيين:(ب) جمالي: يكون الخيال قوة الإنشاء والتركيب لمفردات المدرك العقلي، والمدرك الحدسي، نحو الإنشاء التعبيري وهو الخلق الجمالي، حيث العاطفة وهي مبدأ الأنشاء التعبيري . وظيفي: اختبار الفروض في ترابطات تمنل معطيات الواقع الموضوعي، ومعطيات الموقف الذاتي، والكثف عن العالم الواقعي بأقرب صبغة مطابقة له، وهو عالم تعيش فيه الذات وتعيشه بان واحد، وبذلك تتجسد مركزية الخيال جماليا ووظيفيا في الموقف الجمالي . 
أبحاث المؤتمر العلمي الدولي الثاني نقابة الاكاديميين العراقيين/ مركز التطوير الاستراتيجي التئي

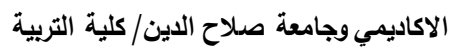

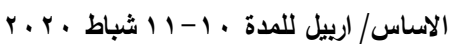
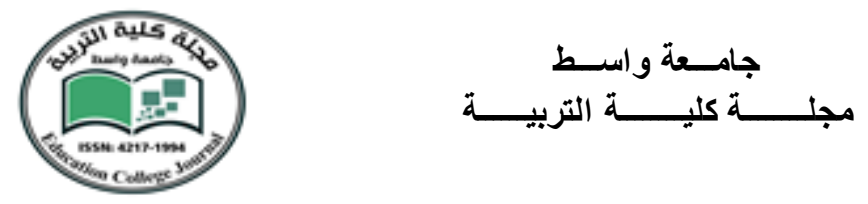

إن تتامي حركة المسرحية وتطور أحداثها يجعل المنلقي(الطفل) في حالة مستمرة من التساؤلات في معرفة كل ما يدور على خشبة المسرح في الاسنمتاع ومعرفة كل ما هو جديد يثري تعلمه بخبرات جديدة، وهذا باعتقاد الباحثة هو (عامل جنب) بحد ذاته، حيث يقع على عاتق المرسل(المصمم) الدور الكبير في تقانة التصميم الذي يبعث على الإثارة ، وبراعة تحقيق عناصر الجنب(الثكل، والمضمون)وما تحمله من رسالة فكرية من خلال صنع المشاهد في إدخال المثيرات البصرية والتي تترك بصمتها الخاصة، والاستجابة على وفق المعطيات الجمالية للعرض في تتامي وتصاعد وبناء كلي للعرض البصري، مما يولد في الطفل إثارة وتشويقاً بعيدا عن كل ما يشوش فكرة العرض من تأثيرات خارجية التي تؤثر في مخاطبة الطفل، المليء بالمفارقات اليومية في الحياة، لذا وجب معالجتها وفق الحلول الملائمة، مع مراعاة تهذيب ذوق المنلقي(الطفل) وشحذ حسه الفني المرهف للوصول الى انتاج عمل قادر على تحقيق عامل الجنب تضع تحت تأثير إبهار المصمم، ومعالجاته للتأطير السينوغراف لنظام العلاقات البصرية وإبداعاته في استثمار تقنيات الجذب البصري، مليئا بالمعاني التي تهيء المنلقي للتجربة الجمالية، فيحصل التواصل مع الخطاب البصري، والطفل عند مشاهدته للمسرحيات المتتوعة يعيد نتكيلة أفكاره في الجمال عبر ما تبثه عناصر الجذب البصري .

\section{المبحث الثاني: الجذب البصري والتراكيب البنائية في العملية التصميمية}

إن لكل عمل فني مكونات بصرية تحمل رؤية فكرية، لذا يسعى الفنان(المصمم) لطرح فكرة وغاية مجسدة من خلال تكوين الشكل والمعنى يتحقق موضوعها مع المدلول والجاذبية الحسية في إحداث أثر نفسي لدى المتلقي، مما يجعل قدرة وعي المصمح بكل قدراته الإدراكية، وخبراته الفعلية أن يتعامل مع العمليات التصميمية في تشكيل بنية العمل ووحدته، وتتوع اتجاهاته التعبيرية، وتنوع علاقاته الدلالية، وتحولاتها الإظهارية لعناصر التكوين ويحولها الى بناءات حسية، تتحكم في المجال الإدراكي، ومدى فاعليتها في التأثير ليرتقي بها، ويسمو عليه شكلا ومضمونا، لذا عند الخوض في مضمار التصميم السينوغرافي للعرض المقدم للأطفال تستوجب الكثف عن معطيات التقافة بكل إرهاصاتها، وأفكارها الجديدة ابتداء من المصمم الذي يعد المحور الأساس الفعال في تشكيل الخطاب البصري، وطريقة عرضه لطروحات العمل التصميمي الناتج عن الخبرة والتجريب لتحقيق غايته وصولا الى التكامل الفني في العرض المسرحي المقدم للأطفال لخلق عالم جميل ومثير يسهم في إنشاء جيل يتذوق الفن والحياة معا . 
أبحاث المؤتمر العلمي الدولي الثاني نقابة

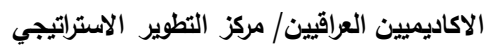

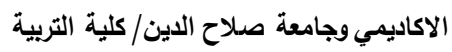

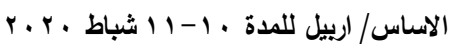
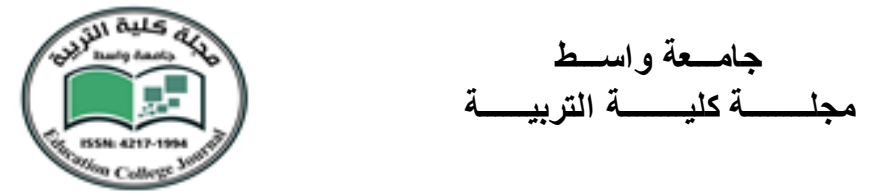

الجنب هي عملية اتصالية، تعاونية، تفاعلية ما بين خبرة المصمم، وميول وأفكار واهتمامات المنلقي (الطفل).قانون الجنب المسرحي، قائم على فرضية(نقيض الثيء)منجنب إليه لأن المتتاقضات في الفن تعطي فرصة عملية لإنتاج حركة داخل الشكل، تسمح للمتلقي بتشكيلها وتوليدها في ذهنه حسب قدرة إدراكه. وتعد العوامل البنائية في فاعلية الجذب والإثارة في عروض مسرح الطفل بدافع جمالي ووجداني محيلة الى مفهوم فكري عن طريق نتظيم العناصر البصرية البنائية، والمعالجات التصميمية للمنظومة البصرية الجاذبة يستطيع العرض البصري الخاص بالطفل أن يستثرها جماليا وفنيا وتعددية المثيرات البصرية وأثرها المساند والجاذب في تصميم وتوظيف هذه العناصر البصرية التي تثير المتلقي(الطفل) في تتمية خياله، إذ إن المنظر السينوغرافيا يتميز بكونه بيئة تحدد زمكانية بناء الجو العام لتحقيق روية وجدانية واعطاء معنى للمثيرات الحسية، وتحقيق هدف العرض في الاسنتاع والفائدة، وإن عملية الترنيب للعناصر البصرية في عروض مسرح الطفل كثيرا ما ثقود الى التعرف على الثكل البصري والذي بدوره يقود الى المعنى، فهو يقود الطفل الى بداية الثعور بالمتعة والفهم، وفي قدرته على استخلاص المعاني من خلال هذه الأشكال البصرية . الصورة التشكيلية البصرية هي عبارة عن حقيقة بصرية كونية تتظم الحياة وتعرض بطرائق وأساليب متعددة، ويختلف الناس في مستوى إنتاجها ودرجة استعمالها وآلية قراءتها بحسب الثقافة والخبرة الفنية، ومداخل الروئة والتفكير، وفن المسرح الأسمى والأكثر شمولا للفنون المتعددة البصرية، والسمعية، والحركية) والدلالية والتركيبية والتنشاركية بنية بصرية منماسكة للمفردات المادية على الخشبة والحضور الحسي في فضاء التخيل وذلك لتحقيق الفروض الجمالية لبناء الثكل المسرحي، إذ وما تحمله من وضوح في الرؤية والتعبير تحقق استقطابا بصريا وما تمنلك من قوة تأثثر فاعل وجاذب للمنلقي باتجاه الثكل، والثكل هو أداة اتصالية مباشرة مؤثرة لمجموعة العناصر البصرية يضمن للمنلقي التواصل بطريقة مشوقة ومعبرة قابلة للإدراك التي تدخل في عملية بناء الكل للمميزات المادية ابتذاء من( النقطة، والخط، والشكل، والحجم، والملمس، واللون، والقيم الضوئية، والاتجاه، والفضاء، والمساحة، والسطوح، والتوازن، والانسجام، والإيقاع، والوحدة .. وغيرها) تعمل على رسم وتتظيم الفضاء التشكيلي السينوغرافيا، والتي يعد إدراكا بصريا حسيا تكتسب ديناميكيتها المتحركة في صورها المرئية تثير المنلقي، كما وتسهم الإضاءة والألوان، وحركاتها الإيقاعية المنتظمة في صيرورة العرض، ويضفي العرض تفاعلية تواصلية، تحمل صورا ناطقة عبر المشاهد المتدقة بتشكيلات صورية لها دلالاتها المختلفة في مجمل عناصر العرض 
أبحاث المؤتمر العلمي الدولي الثاني نقابة

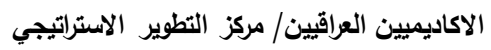

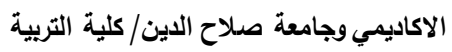

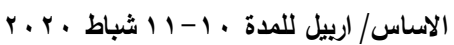
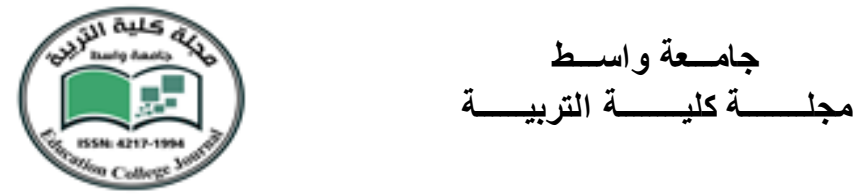

المسرحي مما يحقق قوة إثارية للتصميم في عروض مسرح الطفل، تعمل على توسيع الخطاب الحسي، الكامنة في براعة المنجز التصميمي، وقيمتها الشكلية الجمالية . تستخدم في المسرح مجموعة من التباينات لا سيما في عروض مسرح الطفل، والذي يعتمد مدى إحساس المصمم للمخيلة الإبداعية والجمال في ابتكار وسائل في تشكيل الصورة البصرية المميزة، وغايته هي إحداث الإثارة النفسية التي يجعل من المتلقي بالإرنياح يستوعب الصورة، ويشد انتباهه،

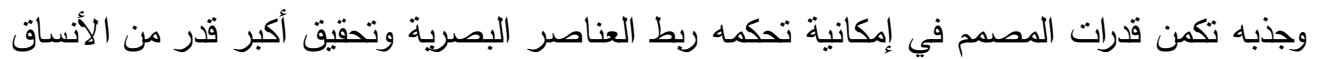
بين الهيئات، وتوزيع وبناء الأشكال، وتقسيم الفضاء، وإعادة تتظيم عمليات التظيم، والتركيب،

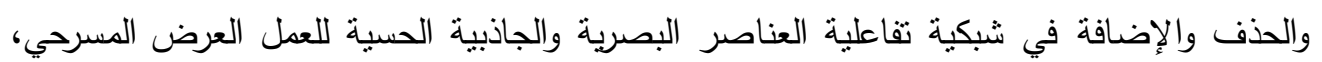
والذي ينطوي على قيم شكلية وتشكيلية، وحركات إيقاعية متتاغمة، وتوافقات في التباين والأضداد، في الأشكال والتي تعد الأكثر فعالية للجنب نشد العين سواء لونية، أو ضوئية، وما تثيره هذه العناصر من دراما تشكيلية يخلقها ذلك التوتر بين تلك العناصر البصرية الجاذبة للمنلقي(الطفل) . إن شكل الأشياء أثند ما يجذب إليه المتلقي(الطفل) ويثير انتباهه، فالثكل هو المدخل لذائقة الطفل الجمالية، البراق، الملون، المتنوع، غير المألوف، فهو لا يبحث في جوهر الأشياء ولا عمّا تتضمنه من أفكار، بل عمّا ينتمي إليه، أو يسعى لأن يكون قريبا منه للعلاقات القائمة والتنظيم

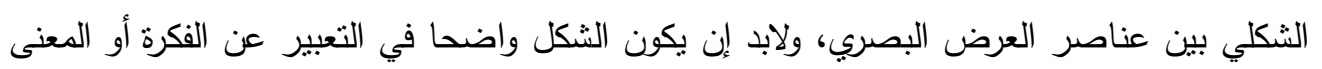
في رسم صورة معبرة وذلك من خلص العناصر البصرية للشكل، والمصمم هو الذي يختار الأشكال على وفق أسس ورؤية في تحديد الثكل، والمضمون، وقدرته الإبداعية في التتظيم والتتاسبية والترابطية بين الأجزاء في كلا موحد ومتجانس، صفة التعلم والتأثر والتقاعل تقترن بنمو الطفل من جهة والمادة المادة المطروحة وطريقة عرضها من جهة أخرى، إذ ينلقى الطفل تجاربه وعبره من الحياة، فهو يعيش في عالم زاخر باللعب والحركة والتخيل والاكتشاف، فيكون في نشاطه أشكالاً بسيطة من المحاكاة والتقليد معتمداً مجموعة من وسائل التعبير التي يشترك فيها السمع والبصر ، وإن وجود الطفل بين أفراد اخرين لهم نفس الهُف يولا حالة نفسية لا تتولد حين يكون الطفل منفردا،

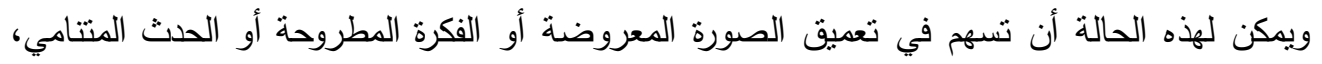
مما ينتج أثره بشكل فوري وعميق، وهذا ما يشير الى العقل الجمعي، الذي غالبا ما يكون تأثيره قويا سواء كان سلبا أم إيجابا، لأن الطفل قد لا يجد مجالا للتقكير الفردي، وهذا الطرح مفيد في إطار الهدف الإيجابي والمدروس في توعيته، حيث يؤدي المسرح دورا تعليميا مرموقا في مجال توجيه

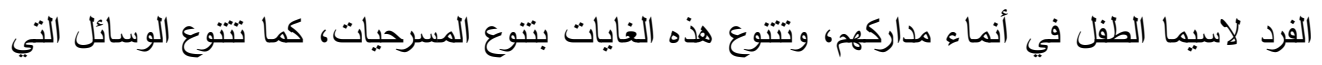


أبحاث المؤتمر العلمي الدولي الثاني نقابة

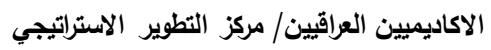

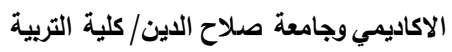

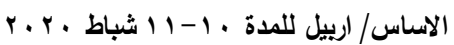
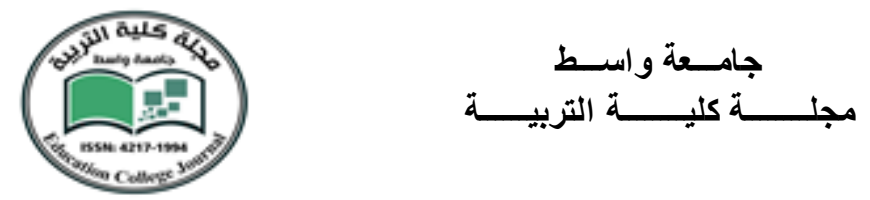

بصطنعها الفنانون للوصول الى هذه الغايات، فهناك من يتكئ على الحث التاريخي أو الديني أو

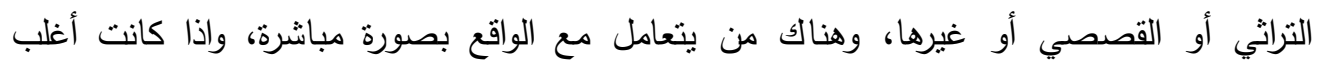

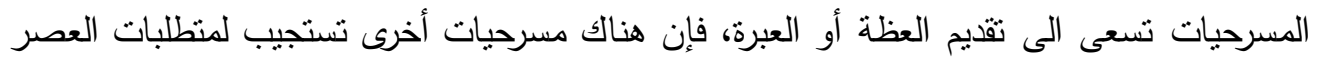

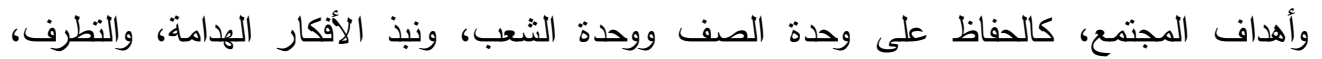

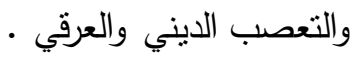

أن الطفل يستجيب للمثيرات القوية أكثر من استجابته للمثيرات الهادئة، وعندما يكون منتبها

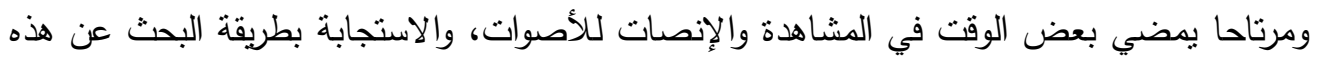

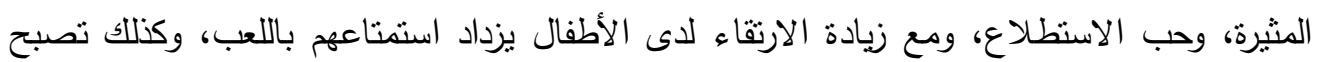

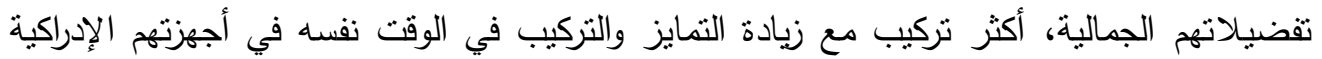

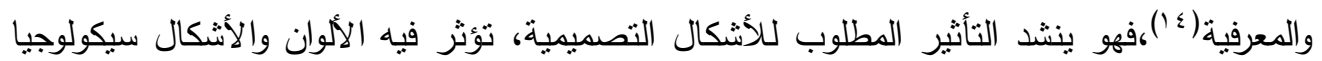

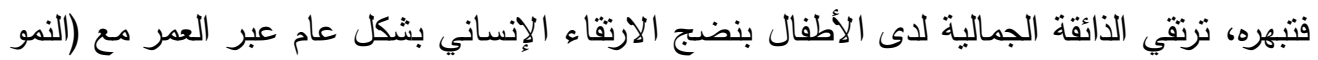

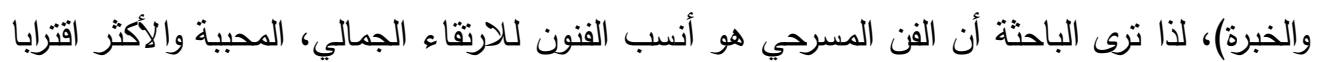

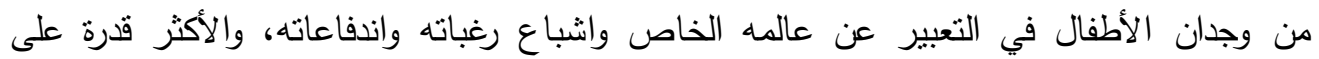
التفاعل والنواصل لما يمنلكه من وحدات تعبيرية متعددة ( السمعية والبصرية والحركية ) وقيم فكرية

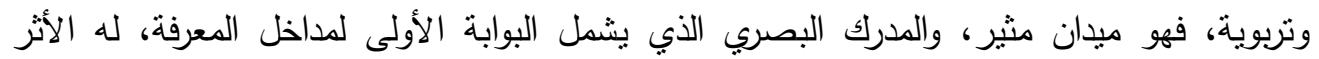

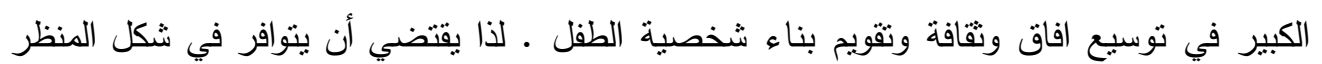
المسرحي المصمم قوتان هما : أولا: الجاذبية: وهي قوة الثد الني ترتبط المنلقي بالمنظر المسرحي الناتجة عن طاقة قوية تتشأ من

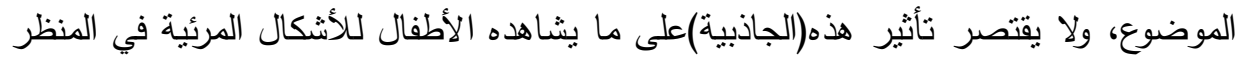
المسرحي فحسب، بل إنها تؤثر في طريقة تتظيم هذه الأثكال، ويطلق على عملية تأثير

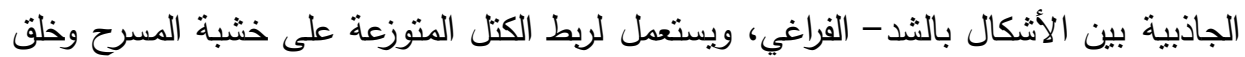
تناسب بين جاذبيتها المطلوبة. ثانيا: قيمة الانتباه : وهي عطلية خلق الانتباه بين المنظر المسرحي والمنلقي، ويقتضي للمصدم إعطاء جميع هيئات الأنشكال في المنظر المسرحي قيمة النتباه كافية تساعد في شد انتباه المنلقي بالنظر (10).

ومن العوامل الرئيسة والأساس لبنية الخطاب البصري(التكرار) يعد عامل جذب دهم، فتخلق تراتبية إيقاعية، ويسهم التكرارات المتعددة في تحقيق الفاعلية للعناصر والأشكال وهذا يرتبط بقدرة المصدم لئه لئه 
أبحاث المؤتمر العلمي الدولي الثاني نقابة

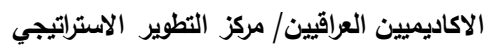

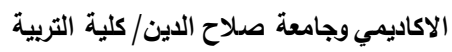

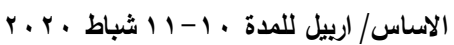
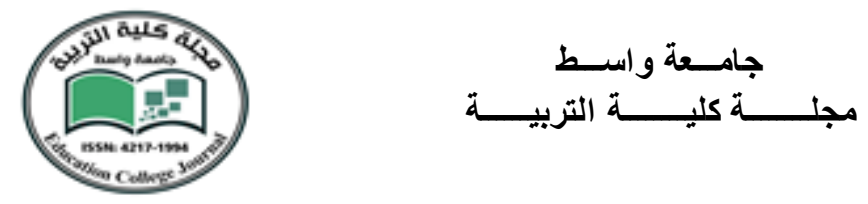

الإبداعية في تتظيم بناء العناصر الحركية المتتوعة لإظهار نواتج حركية متتاغمة بصريا للقوى البنائية للعناصر مع مضمون البنية التصميمية للعرض المسرحي الموجه للأطفال بما يتتاسب أبعاد نظمها، وعلاقتها، خطوطها، وأشكالها وتتاغمها بما يحقق الجنب لثد انتباه المنلقي (الطفل) وسحب بصره للعرض المسرحي، وذلك باستخدام طرائق وأساليب في المعالجات التصميمية على وفق وفه وفي منطلبات نتظيمية تمنلك أكبر قدرا من الجذب في تتظيم حركة كل العناصر في فضاء العرض، وخلق جمالية للمستوى الشكلي التعبيري، لتحقيق انعكاسات فاعلة على مستوى الجذب البصري، وكلما كان العرض المسرحي قريبا الى واقعه، كان الإحساس الجمالي قريبا الى نفسه ورغباته، لذا وجب على المصمم أن يجعل المتلقي(الطفل) مركزا على الجزء المباشر في تركيزه ولا يشتت في الفضاء المسرحي ويبعده عن مضمون المسرحية والتي نريد منها أن تجعل الموضوع مؤثرا في بناء شخصية الطفل .

لعبت التقنيات الحديثة دورا هاما في الجذب من خلال علاقات العناصر البصرية بعضها البعض في خلق فضاءات متعددة تجتمع وتتجانس على وفق المنظومة البصرية وبنائها التي تحمل ذات أبعاد ومفاهيم فكرية وجمالية ونفسية في ضوء معطيات المسرح الحديث بدلالاتها البصرية المتحركة والمتحولة باستمرار لروح العرض في دينامية الفعل وأدائه في إخال تلك المثيرات بما يحمله من عوامل النشويق والجذب" 17 ما أسفر عنه الاطار النظري

ا - الجذب هي عملية اتصالية، تعاونية، تقاعلية ما بين خبرة المصمم، وميول وأفكار واهتمامات - المنلقي (الطفل)

r - يبنى قانون الجذب البصري على قوة التفاعل ما بين المرسل •العرض) والمرسل اليه(المتلقي) بصريا وفكربا

r - قانون الجذب المسرحي، قائم على فرضية(نقيض الشيء)منجذب إليه لأن المتتاقضات في الفن تعطي فرصة عملية لإنتاج حركة الشكل، تسمح للمنلقي بتشكيلها وتوليدها في ذهنه حسب قدرة إدراكه.

ـ - يعد المثير البصري عاملا مهما في توصيل وفهم المعنى للصورة البصرية الجاذبة في عروض مسرح الطفل . مسل ه - يساعد التتوع في الأشكال البصرية المجتمعة أو المنفردة أو المعزولة أو المتقاربة مكانيا الثابتة أو المتحركة على تحقيق المثير البصري للعرض المقدم للأطفال . 
أبحاث المؤتمر العلمي الدولي الثاني نقابة

الاكاديميين العراقيين/ مركز التطوير الاستراتيجي التئي

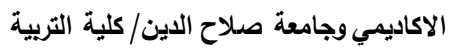

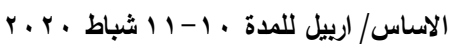
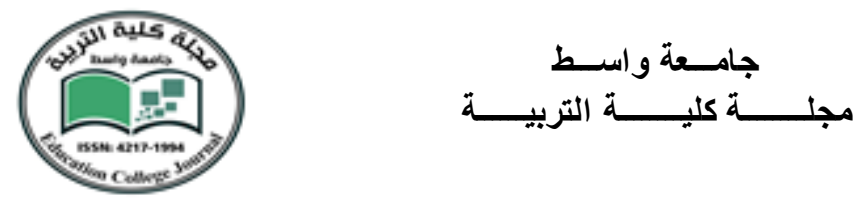

ج - عناصر العرض البصرية وحدة مهمة في اشتغال التفاعل ما بين العرض، لللك يشكل

$$
\text { (اللون) المعادلة الأقرب للطفل . }
$$

V - تساهم كل من الإضـاءة والألوان في صبرورة العرض من خلال الصورة الناطقة تضفي العرض

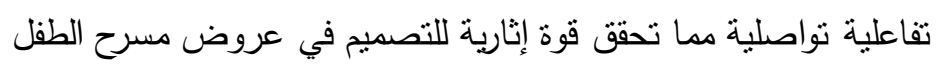

1 - التفاوت في درجات الإضاءة والألوان مع الموسيقى المغايرة يولد جذبا وتشويقا في فضاء العرض لـاء

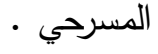

9 - يحقق التتافر والتضاد، والإختلاف في زي الثخصيات جذبا وتأثيرا في عروض مسرح الطفل . • 1 - تؤدي منظومة الماكياج والملحقات الثخصية للمثنل وظيفة جمالية في إيضاح وإخفاء الملامح

\section{الفصل الثالث : إجراءات البحث}

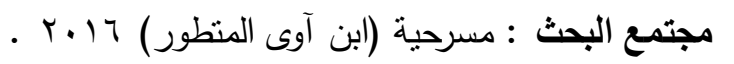

عينة البحث : تم اختيار عينة للمخرج والسينوغراف (ذو الفقار البلداوي)، اختبارا قصديا لأنها تمثل مجتمع البحث ، ولأن الباحثة قد شاهدتها على المسرح ، ولتوفر عناصر الجنب والمثير

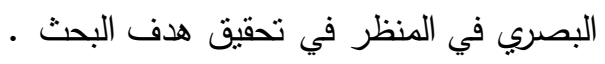

منهج البحث : اعتمدت الباحثة المنهج الوصفي(لتحليلي) في تناول الإطار النظري وإجراءات البحث، وذلك لاتساقه مع مسار البحث وغايته، لغرض التحليل وصولا لتحقيق أهداف البحث، والكشف عن حقائق علمية وموضوعية، تبنى على أساسها المرتكزات التصميمية، ومؤثرات الجذب

$$
\text { أبصري • البصات البحث : }
$$

لغرض تحقيق هدف البحث اعتمدت الباحثة على ما يأتي :

أ - الوثائق: الكتب، الرسائل والأطاربح، المجلات، الدوربات، الأقراص المدمجة(CD) . ب - معطيات ومؤشرات ما أسفر عنه الاطار النظري .

ت - المقابلات الشخصية : مع مخرج ومصمم العرض المسرحي •

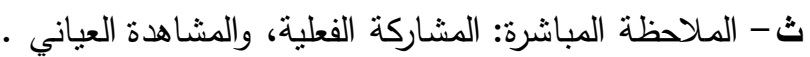
تحليل العينة : عن المسرحية وأفكارها :

مسرحية تعليمية ترفيهية قدمت بشكل كوميدي لتصل المعلومة الى المتلقي(الطفل) بسهولة ويسر، تتاقش موضوع القوة في الصدق عند الانسان،(النجاة في الصدق)، وعدت فكرة المسرحية من 
أبحاث المؤتمر العلمي الدولي الثاني نقابة

الاكاديميين العراقيين/ مركز التطوير الاستراتيجي التئي

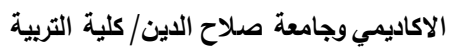

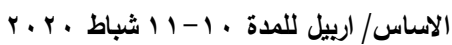
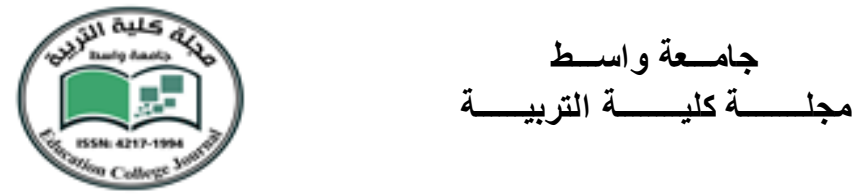

المسرحيات الأخلاقية اذ على أهية الصدق وعدم الكذب والخداع مع الآخرين، وأن الكنب حبله

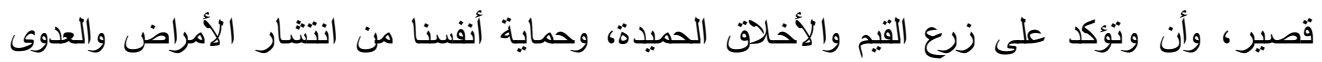
مرض (أنفلونزا الطيور) إذ يقوم(ابن آوى) بخداع الناس، ويدعي بأن لديه (الدواء الثافي) اللقاح المضاد للمرض وذلك للاستيلاء على (صغار الحمام)ويستمر بالخداع والمكر في إقناع(طير برع الحمام)أن هناك مرضا فتاكا يقضي على صغارها، وأن العلاج لديه، حيث يتتكر بملابس ومظهر جديد معاصر، وتحاول(الفراشة) الصديقة المحببة والمتعاونة بكل الوسائل في إثبات أن ( أبن آوى) ماكر وخداع الذي يخدع الآخرين بلسانه المعسول المزيف، واستطاع (أبن آوى)بمكره وزيفه في اختطاف صغار الحمام، مما جعل من طائر الحمام في حزن شديد على فراق أولاده، فتتعاون كل من(الفراشة) وصديقتهم(زهرة الثمس) للمحاولة في استرجاع صغار الحمام، وبالفعل تتجح خطة كل من(الفراشة) و (زهرة الشمس) وتأمر (زهرة الشمس) في إقامة محكمة لمحاكمة(أبن آوى) على فعلته الثنيعة النكراء، فتطلب من الأصدقاء (الأرانب) للحضور في إقامة محكمة للماكر ( أبن آوى) ومن ثم أث أصدار الحكم على(أبن آوى) أن يأكل(الجزر والتفاح) طيلة ما تبقى من حياته، فيبكي (أبن آوى) ويترجى الصفح والعفو أمام الجميع، وعدم تكرار ما فعله، وبعد المداولة يصفح عنه(طائر الحمام) فيقترب في هذه الأثناء (أبن آوى) مرة أخرى بمكره وزيفه من خطف أحد صغار الحمام ويلوذ بالفرار، فتحاول جميع الحيوانات بالجري خلف(أبن آوى)وإقاء القبض عليه واسترجاع صغير الحمام، وإدخاله في السجن، ليكون عبرة لكل من يخدع الآخرين • أمتلك العرض المسرحي من خلال القصة المعبرة والهادفة معايير فكرية وجمالية من خلال أداء الممتلين، وحركاتهم السريعة الجاذبة للمتلقي (الطفل) والجاذبية الواضحة لمجموعة من القيم الواضحة للبنى الثكلية الثاغلة لفضاء العرض البصري من رسومات، وما حملته من وضوح في الرؤية والتعبير، وما امتلكت من قوة نأثثر فاعل وجاذب لشروط نكوين الشكل الحقيقي هو(الوضوح، والتحديد) وقيم دالة في الفهم لمفردات العرض أعطى انطباعا حقيقيا عن الحيوية المعبرة في استعمال كل إمكانيات الثكل متكاملا ومعبرا للفكرة المراد ايصالها للمتلقي(الطفل)، والثكل البصري في إنتاج دلالات ومعاني عملت على تحقيق جذب المتلقي(الطفل) . أدت الأزياء دورها الوظيفي والجمالي في عملية الجذب بنطال قصير (أصفر) اللون، وقميص طويل، مع قناع رأس طير حمام مفتوح(تجويف الفم) مع وضع عباءة قصيرة على الكتف لتمنل جناح الطائر، وتمثل زي(الفراشة) من رداء طويل مع جناحين(أبيض) اللون وطوق(أبيض)، أما زي(زهرة 
أبحاث المؤتمر العلمي الدولي الثاني نقابة

الاكاديميين العراقيين/ مركز التطوير الاستراتيجي التئي

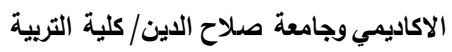

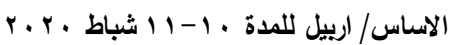
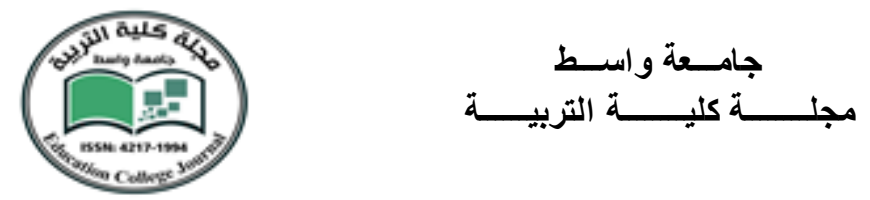

عباد الثمس) قميص طويل(أخضر) فاتح ولماع، وبنطال قصير، مع شرائط بيضاء، أما زي(أبن

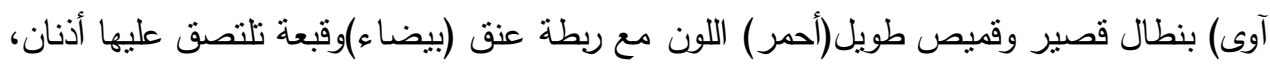

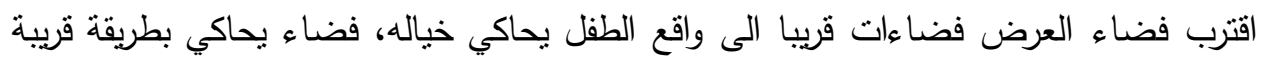

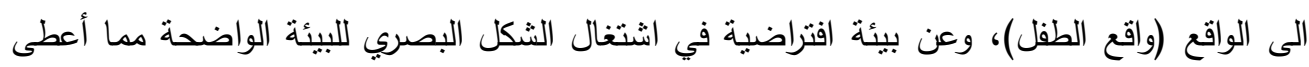

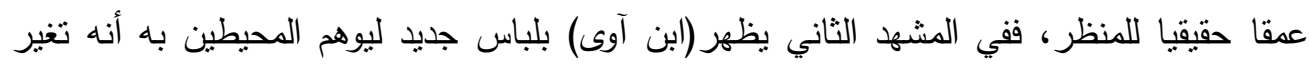

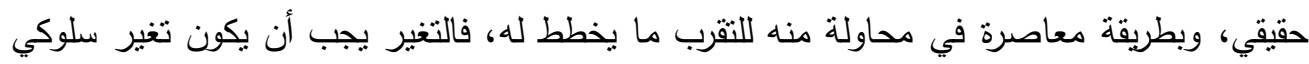

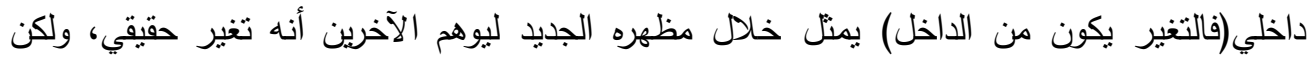

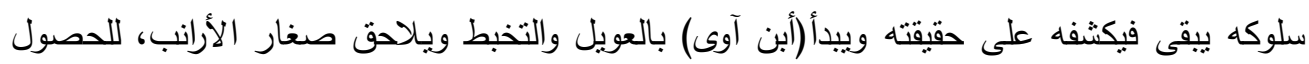

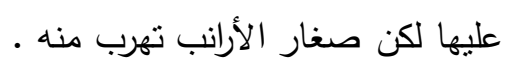

أحتوى العمل من خلال تتاسق ألوان المنظر مشاهد بصرية أثرت محتوى العمل إمتاعا وجذبا،

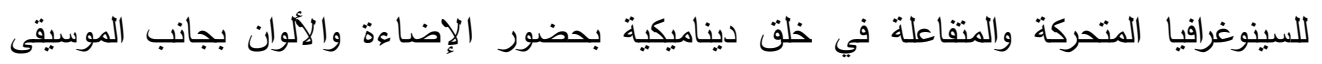

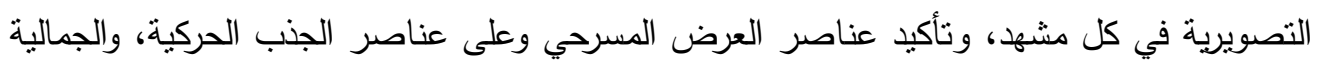

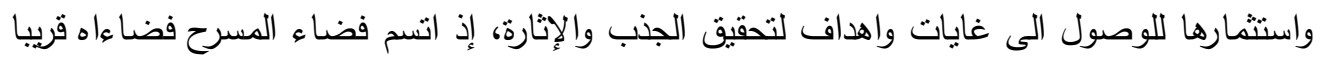
الى واقع الطفل، فضلا عن اضفاء الطابع الاحتفالي . - -

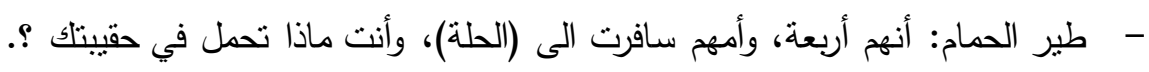
- أبن آوى: إنه حقيبة (آوى توب) نسبة الى (لا بتوب). . وهنا أثنار الضحك لدى المنلقين (الأطفال)..

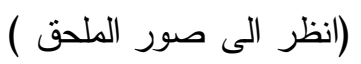

يضع(أبن آوى) بمكره أحد صغار الحمام وخطفه(أبن آوى) في كيس من القماش ليخفيه عن

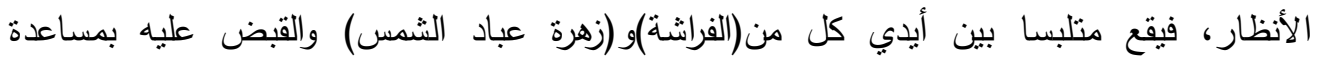

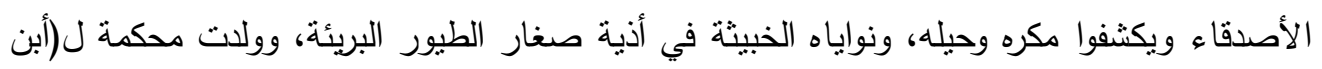

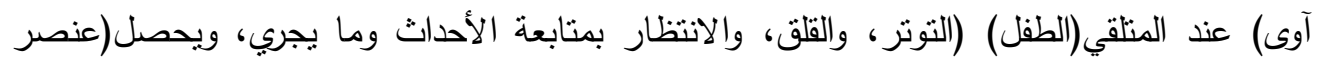

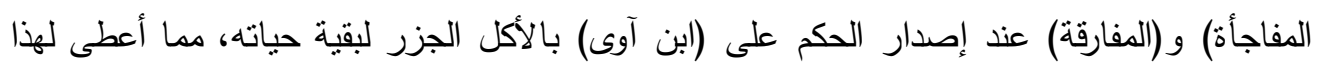

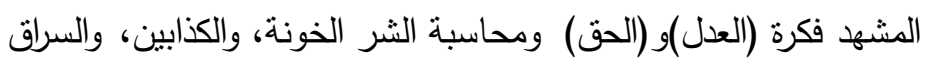

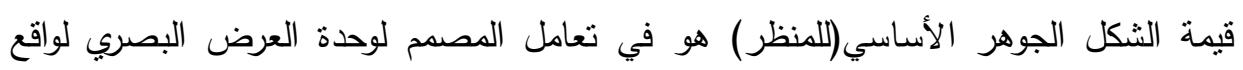

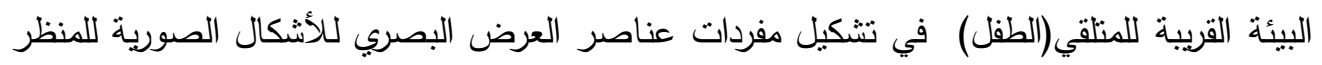


أبحاث المؤتمر العلمي الدولي الثاني نقابة

الاكاديميين العراقيين/ مركز التطوير الاستراتيجي التئي

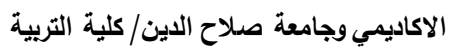

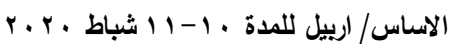
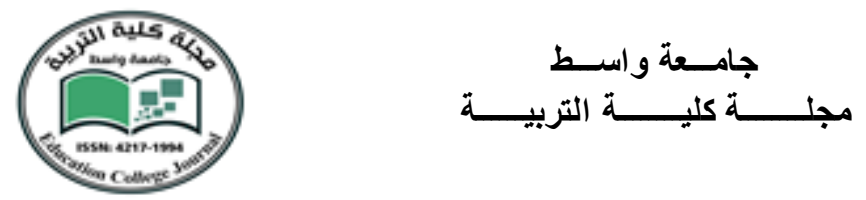

في تموضع الكتل المتتاسبة على جانبي المسرح ووسطه مع مرونة حركة الممثل، وتتقلاته السريعة مما حقق شدا وجذبا وانتباها، في تقاعل الأطفال مع الشخصيات(الحيوانية) والتي تحولت الى شخصيات ناطقه تتحاور وتتمازح وتركض منل الإنسان، وأضاف المصمم السينوغراف مسحه جمالية

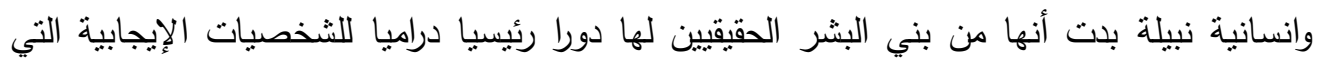
تكون منقادة لرغبات وهجمات الأشرار مما يجعل المنلقي (الطفل) يتعاطف مع هذه الشخصيات الحيوانية والتي حققت ايقاعا متتوعا للخطاب البصري على خشبة المسرح، وكذلك كان اختفاؤهم وظهورهم خلف الواح الأشجار الملونة حققت خطابا تواصليا لعناصر الجذب البصرية الحركية مع • المتلقي(الطفل)

حققت الإضاءة والألوان دورا هاما في تأديتها على تجسيد نسق الحركات الإيقاعية الراقصة في الشكل المسرحي والتحكم بإسقاطها على الأشكال والكتل الثابتة والمتحركة، ، وزيادة سرعة الإيقاع بتتقلاتها المختلفة وخطوطها اللونية الانسيابية المتتوعة بشكل يتفق مع الروئية الإخراجية، إذ عد اللون عامل حسي له دلالاته المتتوعة عند المتلقي(الطفل)وكذللك المفردات المادية الأخرى على الخشبة والتحكم بالثدة والكثافة واللون في تشكيل الخطاب البصري لأجل خلق فضاء التذاعي للفروض دلانه الخيالية في البناء الجسدي للحركة، وابراز عنصر السيادة للشخصيات الأخرى من خلال الإضاءة والألوان للبقع الضوئية المنوزعة على خشية المسرح كشخصية(أبن آوى)المشاكس(السلبي) الذي يثير المشاكل، المعبر عن العنف والمؤامرة، وشخصية(الفراشة)(الإيجابي)،الشخصية المحبة المتعاونة في وسط المسرح، وهنا برزت عدة معايير ومفاهيم ودلالات تربوية، وأخلاقية واستخلاص الدروس والعبر

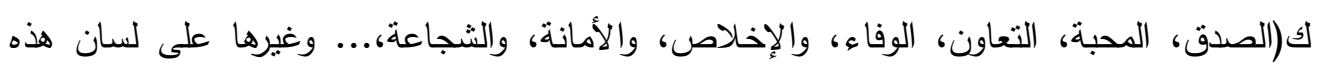
الشخصيات الايجابية (الفراشة)و (زهرة عباد الثمس) للتغلب على المشاكل الحياة اليومية والوصول الىى الحلول الصحيحة، مما يجعل المنلقي (الطفل) بدرك من خلال الإصغاء ومتابعته لتسلسل

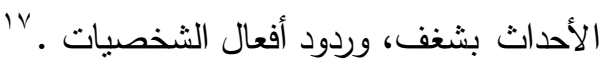
حققت الموسيقى والمؤثرات الصوتية تأثثرا وجذبا واضحا، وعد الإيقاع السمعي بجانب الايقاع البصري والحركي من خلص الأغاني، ونوظيفها والتركيز على فلكلوريات أغاني الأطفال القديمة للأحداث والتي شكلت عامل جذب ونتويق، كما لعبت لغة الحوار دورا أساسيا مع الموسيقى والمؤثرات الصوتية في تأكيد الموقف التفسيري وربط المشاهد، والأفعال، والأحداث، وعلاقات الشخصيات وحركاتها الإيقاعية، تأثيرات مباشرة وآنية، حققت تفاعل الأطفال مع هذه الشخصيات وإمتاعهم للمواقف الدرامية، والإيقاعات السمعية، في التعاطف والتشويق، وتحريك مشاعره، مما تشبع 
أبحاث المؤتمر العلمي الدولي الثاني نقابة

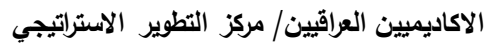

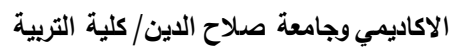

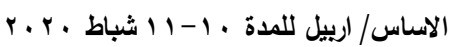
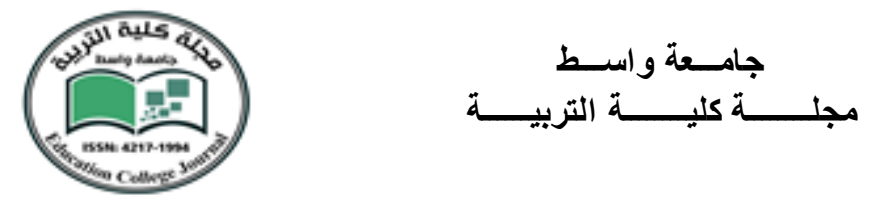

حاجاته ونوازعه السيكولوجية وتوسيع مداركة الحسية للمثيرات البصرية والتخفيف من الضغوطات

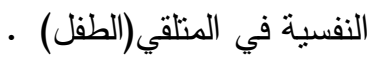

ا -أعتمد العرض على نص بصري منطوق بما يتتاسب الموضوع والأحداث في علاقات بنائية تنظيمية لمعادلات التصميم عناصر العرض البصري الجانب مما حققت الاثارة والادراك الحسي عند - المتلقي (الطفل) ץ-ساهمت الإضاءة والألوان في صيرورة العرض، والتي أضفت العرض تفاعلية نواصلية، حملت صورا ناطقة عبر المشاهد المتدققة بتشكيلات الصورية مما تحققت قوة إثارية للتصميح . r - أدت التفاوت في درجات الإضاءة والألوان مع الموسيقى المغايرة جذبا ونتويقا في فضاء العرض ع -حققت الموسيقى والمؤثرات الصوتية تأثيرا وجذبا واضحا مع حوار الثخصيات في ربط الأحداث مما حقق جذبا وتأثيرا واضحا على المتلقي(الطفل) مانى ه -أضافت منظومة الماكياج والملحقات، للشخصيات الحيوانية جذبا في ابرازها الوظيفي والجمالي في

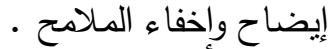
7 - أدت تتاسق الشكل التصميمي ل(الأزياء، والماكياج، الأقنعة، والإكسسوار)أبعادها الاجتماعية، والنفسية، والوظيفية، وتركييتها السيكولوجية، وعلاقاتها التواصلية، التي ساعت على جذب

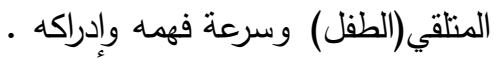

إقامة دورات وورش تدريبية للمهتمين والمقيمين على مسارح الطفل . المقترحات

(اشتغال عوامل الجذب للتقنيات البصرية الحديثة في عروض مسرح الطفل) 
أبحاث المؤتمر العلمي الدولي الثاني نقابة الاكاديميين العراقيين/ مركز التطوير الاستراتيجي التئي

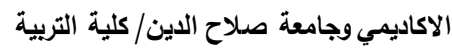

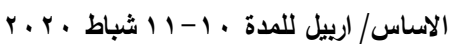

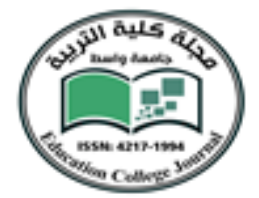
جامــعة و اســط كلـ

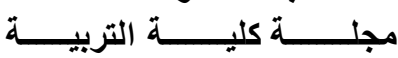

\section{الملحقات}

مسرحية (ابن آوى المنطور) صورة رقم (1)

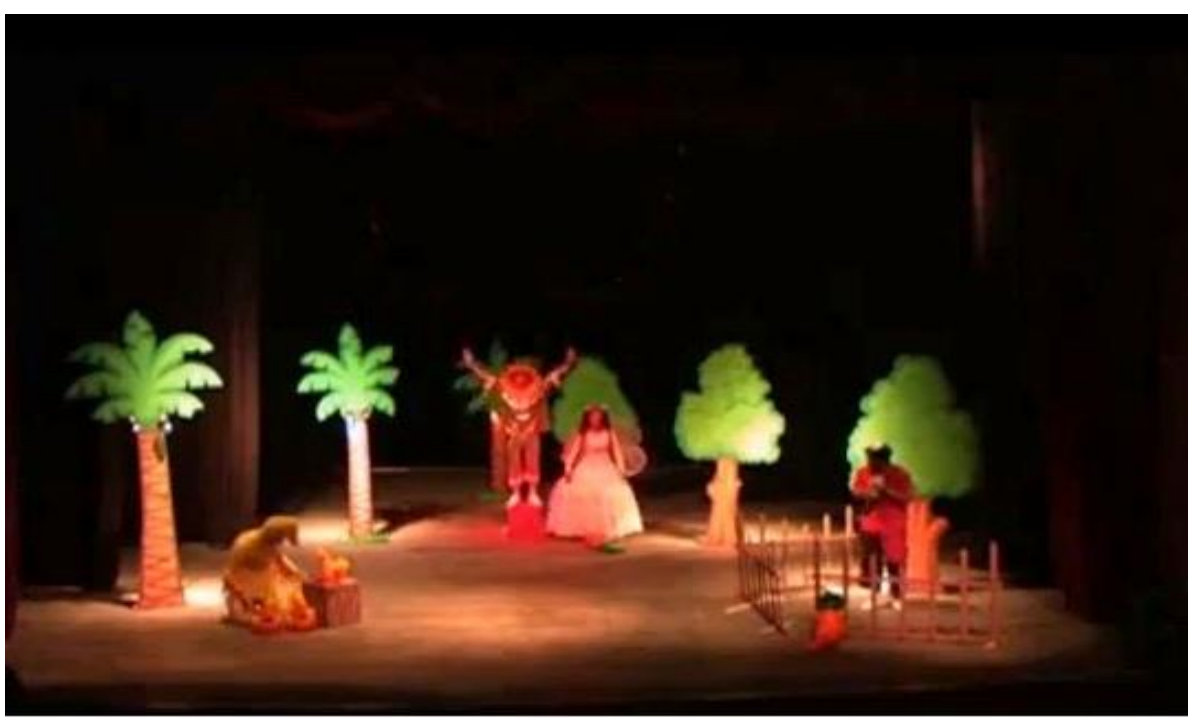

مسرحية (ابن آوى المتطور) صورة رقم (ץ)

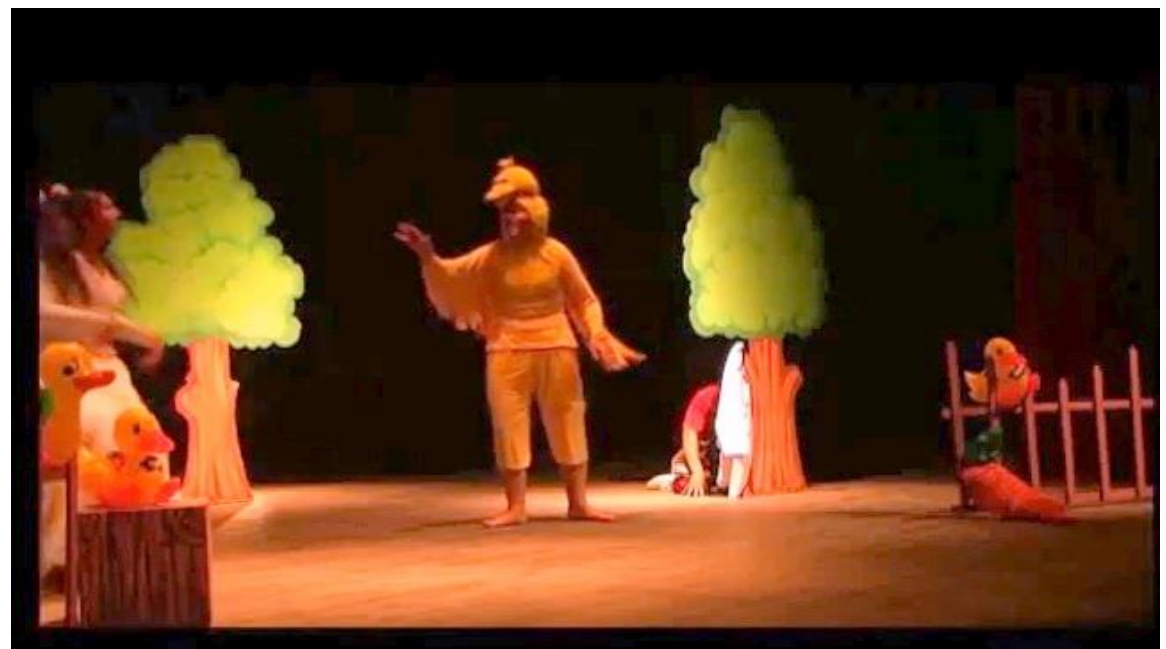


أبحاث المؤتمر العلمي الدولي الثاني نقابة

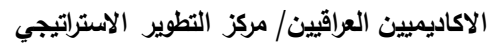

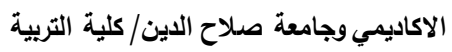

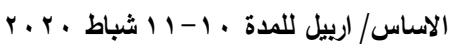
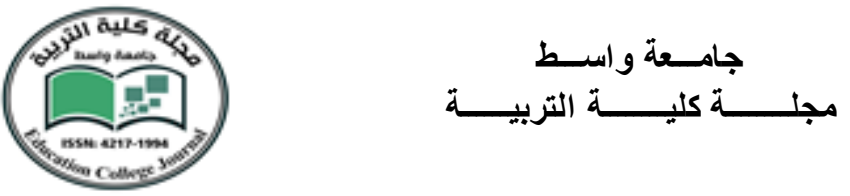

المصادر والمراجع

1- الباجلان، ميادة مجيد، جماليات نوظيف السينوغرافيا في عروض مسرح الطفل(دائرة الطباثير الملونة انموذجا)،

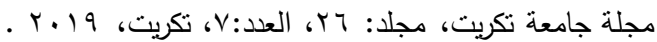

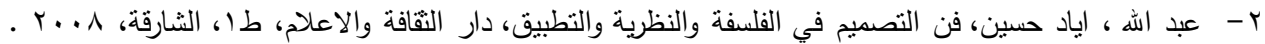

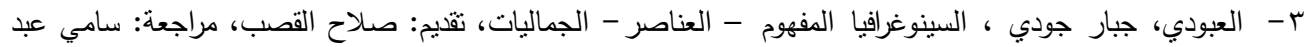

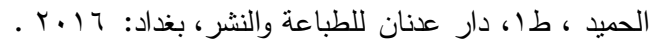
ع - الليثي، ثابت رسول، جماليات الواقعية الخيالية في عروض المسرح العزان العراقي، اطروحة دكتوراه، جامعة بخداد، كلية

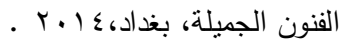

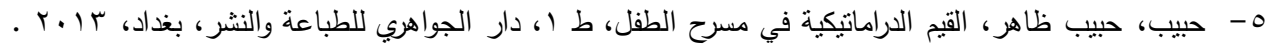

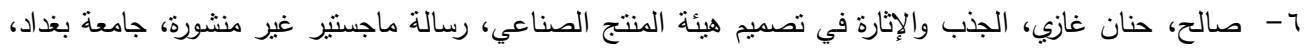

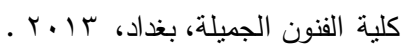

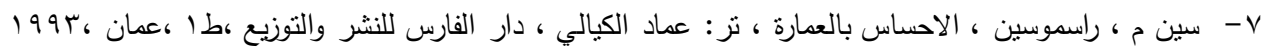
^- عبد الحميد، شاكر ، التفضيل الجمالي ، دراسة في سيكولوجية التذوق الفني، عالم المعرفة، (سلسلة شهرية) يصدرها

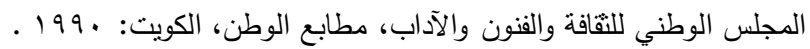

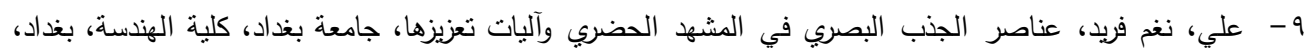
.r..人 • 1- عطية، احمد سلمان، الاتجاهات الاخراجية وعلاقتها بالمنظر المسرحي، دار صفاء للطباعة والنشر، طا، الاردن، .$r \cdot I r$

ال1-وارد، وينفريد، مسرح الأطفال، تر: محمد شاهين الجواهري، مر: كامل يوسف، المؤسسة المصرية العامة للتأليف

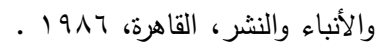

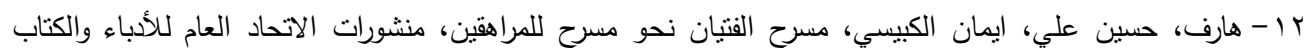

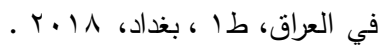

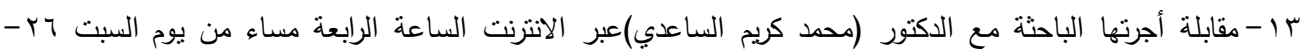
$. r \cdot 11-0$ 
أبحاث المؤتمر العلمي الدولي الثاني نقابة الاكاديميين العراقيين/ مركز التطوير الاستراتيجي التئي

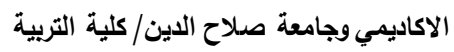

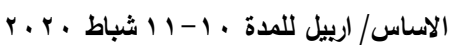
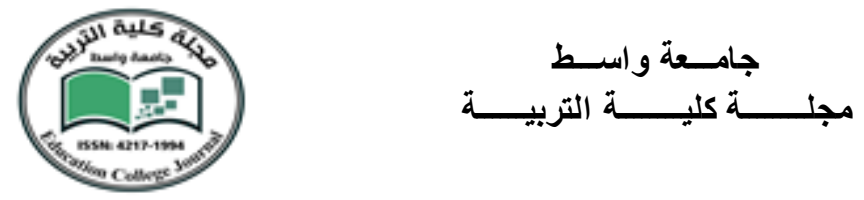

الكهوامش

( ) - -علي، نغم فريد، عناصر الجذب البصري في المشهد الحضري وآليات تعزيزها، جامعة بغداد، كلية الهنسة، بغداد،

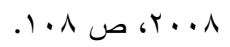

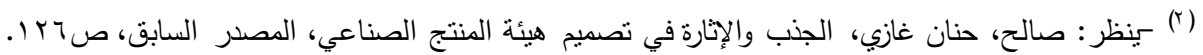

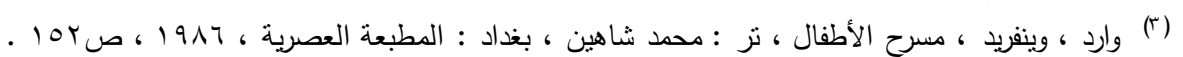

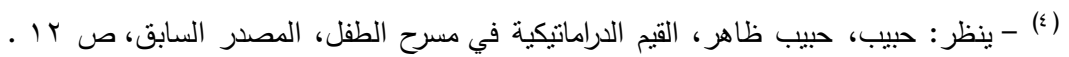

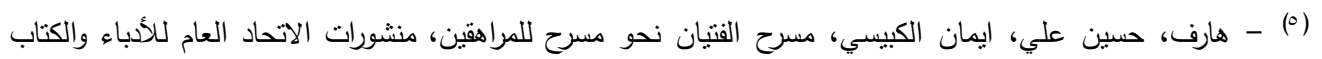

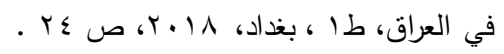

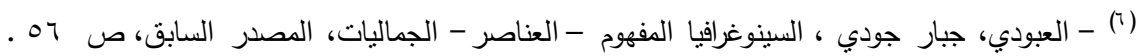

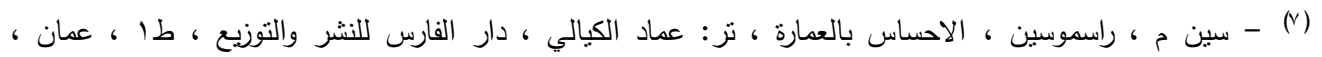

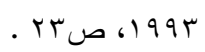

(^) -وارد، وينفريد، مسرح الأطفال، تر: محمد شاهين الجواهري، مر: كامل يوسف، المؤسسة المصرية العامة للتأليف

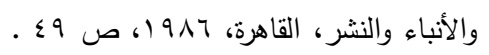

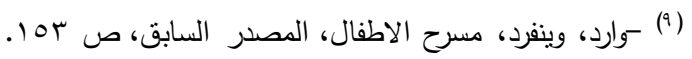

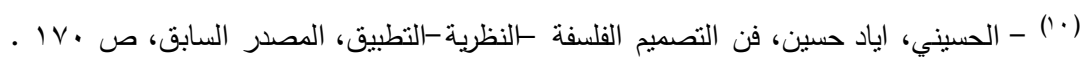

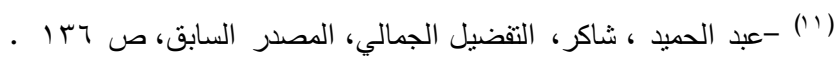

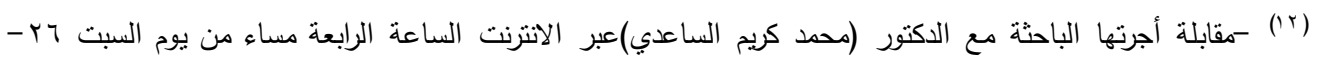

.$T \cdot 11$

(rا') سينظر: الليثي ، ثابت رسول، جماليات الواقعية الخيالية في عروض المسرح العراقي، المصدر السابق، ص .ب-

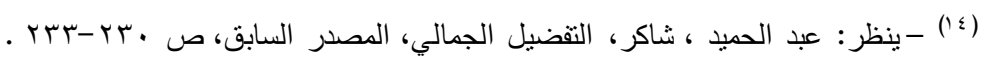

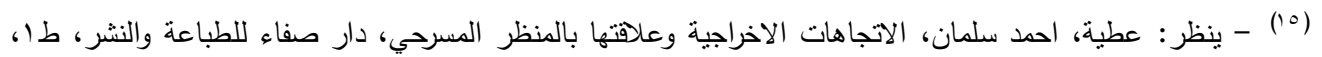

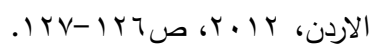

17 كينظر: الباجلان، ميادة مجيد، جماليات نوظيف السينوغرافيا في عروض مسرح الطفل(دائرة الطباشبير الملونة

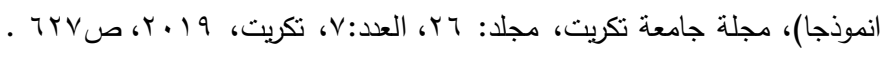

